\title{
Validation of a new signal processing scheme for the MST radar at Aberystwyth
}

\author{
D. A. Hooper ${ }^{1}$, J. Nash ${ }^{2}$, T. Oakley ${ }^{2}$, and M. Turp ${ }^{2}$ \\ ${ }^{1}$ Space Science and Technology Department, STFC Rutherford Appleton Laboratory, OX11 0QX, UK \\ ${ }^{2}$ Observations Division - Upper Air Team, Met Office, EX1 3PB, UK
}

Received: 18 October 2007 - Revised: 2 June 2008 - Accepted: 29 August 2008 - Published: 21 October 2008

\begin{abstract}
This paper describes a new signal processing scheme for the $46.5 \mathrm{MHz}$ Doppler Beam Swinging windprofiling radar at Aberystwyth, in the UK. Although the techniques used are similar to those already described in literature - i.e. the identification of multiple signal components within each spectrum and the use of radial- and time-continuity algorithms for quality-control purposes - it is shown that they must be adapted for the specific meteorological environment above Aberystwyth. In particular they need to take into account the three primary causes of unwanted signals: ground clutter, interference, and Rayleigh scatter from hydrometeors under stratiform precipitation conditions. Attention is also paid to the fact that short-period gravitywave activity can lead to an invalidation of the fundamental assumption of the wind field remaining stationary over the temporal and spatial scales encompassed by a cycle of observation. Methods of identifying and accounting for such conditions are described. The random measurement error associated with horizontal wind components is estimated to be 3.0$4.0 \mathrm{~m} \mathrm{~s}^{-1}$ for single cycle data. This reduces to $2.0-3.0 \mathrm{~m} \mathrm{~s}^{-1}$ for data averaged over $30 \mathrm{~min}$. The random measurement error associated with vertical wind components is estimated to be $0.2-0.3 \mathrm{~m} \mathrm{~s}^{-1}$. This cannot be reduced by time-averaging as significant natural variability is expected over intervals of just a few minutes under conditions of short-period gravitywave activity.
\end{abstract}

Keywords. Meteorology and atmospheric dynamics (Mesoscale meteorology; Precipitation; Waves and tides) Radio science (Remote sensing; Signal processing)

Correspondence to: D. A. Hooper

(david.hooper@stfc.ac.uk)

\section{Introduction}

Atmospheric radars which operate at frequencies of around $50 \mathrm{MHz}$, i.e. at lower-Very-High-Frequency (VHF), are primarily sensitive to backscatter from metre-scale refractive index irregularities (Woodman and Guillen, 1974). The latter are advected with the three-dimensional wind. Consequently the radial component of the wind velocity, $v_{R}(\theta, \phi)\left(\mathrm{m} \mathrm{s}^{-1}\right)$ :

$v_{R}(\theta, \phi)=u \sin \theta \sin \phi+v \sin \theta \cos \phi+w \cos \theta$

i.e. that along the beam-pointing direction - where $\theta\left({ }^{\circ}\right)$ is the (off-) zenith angle and $\phi\left({ }^{\circ}\right)$ is the azimuth angle, and $u, v$ and $w\left(\mathrm{~m} \mathrm{~s}^{-1}\right)$ are the eastward, northward and upward components of the wind, respectively - can be determined from the Doppler shift of the so-called clear-air radar return signal. Radar returns are typically sampled over the altitude range $2-20 \mathrm{~km}$ at intervals of a few hundred metres. Profiles of the three-dimensional wind vector can be derived using the Doppler Beam Swinging (DBS) technique. Observations are made sequentially in a minimum of three non-coplanar beam-pointing directions. A common implementation is the three-beam format. Observations are made in the vertical direction and at two off-vertical directions with the same small zenith angle (which is typically around $10^{\circ}$ ) but with azimuth angles which are separated by $90^{\circ}$. The vertical beam observation provides a profile of the upward wind component. This can be combined with the profile of the radial component for each off-vertical beam observation to provide a component of the horizontal wind along the azimuth of the offvertical beam, i.e. $v_{H}(\phi)=u \sin \phi+v \cos \phi\left(\mathrm{m} \mathrm{s}^{-1}\right)$ :

$v_{H}(\phi)=\frac{v_{R}(\theta, \phi)-w \cos \theta}{\sin \theta}$

The five-beam format provides redundancy for the horizontal wind estimates by making additional observations in

Published by Copernicus Publications on behalf of the European Geosciences Union. 
the complementary off-vertical directions, i.e. those separated by $180^{\circ}$ in azimuth from each of the first pair. Two complementary-beam observation volumes are separated by a horizontal distance of $2 r \sin \theta(\mathrm{m})$, where $r(\mathrm{~m})$ is the range from the radar. This is the order of a few $\mathrm{km}$ at a range of $10 \mathrm{~km}$. Each observation in a different beam-pointing direction, known as a dwell, requires measurements to be accumulated over the order of a few tens of seconds. A typical cycle of observation therefore lasts a few minutes. A central assumption of the DBS technique is that the three-dimensional wind-field remains stationary over the spatial scales separating the different radar observation volumes and over the temporal scale of a cycle. Although this is largely true, this paper will focus on those conditions under which the assumption is invalid.

The DBS technique can also be applied to radars operating at frequencies of around 400 and $1000 \mathrm{MHz}$. One of the principal differences is that such radars are additionally sensitive to Rayleigh scatter from hydrometeors (e.g. Larsen and Röttger, 1987; Ralph, 1995). Under conditions of precipitation, the vertical beam observations tend to give a measure of the fall speed of the hydrometeors and not of the vertical wind. Nevertheless, the hydrometeors can still be assumed to act as a reasonable tracer for the horizontal wind (e.g. Wuertz et al., 1988).

Advances in quality-control techniques over the past three decades have led to the accuracy of radar-derived horizontal winds (e.g. Larsen, 1983; Weber and Wuertz, 1990; Thomas et al., 1997; Luce et al., 2001; Dibbern et al., 2003a) becoming comparable to that of radiosonde measurements (e.g. Kitchen, 1989; Nash, 1994). Moreover wind-profiling radars are typically operated on a continuous basis and can provide wind-profile data at intervals as short as just a few minutes. By contrast, radiosondes cannot be launched during conditions of strong surface winds (when measurements are most needed) and they are rarely launched at intervals of less than $6 \mathrm{~h}$ (intervals of $12 \mathrm{~h}$ are more common in the UK). Consequently there has been considerable interest in making operational use of the radar data by national weather services. In the US this has led to the development of a demonstration network of over thirty profilers by the National Oceanic and Atmospheric Administration (e.g Strauch et al., 1984; Barth et al., 1994). A similarly-sized operational network exists in Japan (e.g. Ishihara et al., 2006). The spread of windprofilers in Europe was initially less concerted, with the level of interest varying from country to country. Nevertheless a de facto network has grown out of the COST-74 (Lafaysse, 1994) and COST-76 (Dibbern et al., 2003b) projects; COST is the abbreviation for "European co-operation in the field of scientific and technical research". As part of COST76, 25 wind-profilers from 10 countries participated in the network (Nash and Ruffieux, 2003).

One of the radars which has contributed to this European network is the UK's $46.5 \mathrm{MHz}$ Mesosphere-StratosphereTroposphere (MST) radar at Aberystwyth (Slater et al., 1992;
Vaughan, 2002). It was designed for research purposes and began operations in 1990 using a variety of observation formats. Since each of these was based around a three- or five-beam sequence, using a zenith angle of $6.0^{\circ}$ for the offvertical observations, wind-profile data were available irrespective of the precise format being used. Although the radar was initially operated for only a few days at a time, since October 1997 it has been observing on a quasi-continuous basis using variations on the five-beam format.

The (UK) Met Office began to evaluate the potential of the Aberystwyth wind-profile data for assimilation into a numerical weather prediction model at an early stage (Nash, 1994). This led to gradual improvements being made to a version0 (v0) signal processing scheme over the period 1990-2000. Although this scheme was robust and gave data of a sufficiently high quality for the Met Office to assimilate them operationally, it was limited by its fundamental simplicity. Many aspects had remained unchanged since 1990, when relatively-limited computer power was a key consideration in design of the algorithms. Consequently, in order to further increase data quality, it was necessary to go back to first principles and to develop an entirely new signal processing scheme. This went through two off-line incarnations (versions 1 and 2) before a version-3 (v3) scheme began operating in parallel with the v0 scheme in January 2006. This allowed the Met Office to evaluate the quality of both data streams, for a period of 12 months, by calculating monthly comparison statistics against model wind fields. For the first seven months, only data from v0 scheme were actually assimilated. The v3 data were assigned a test status. However, the consistently superior performance of the $\mathrm{v} 3$ scheme over this early period (Hooper et al., 2007) persuaded the Met Office to switch over to data from the $\mathrm{v} 3$ scheme for operational assimilation in August 2006.

The purpose of this paper is to validate the $\mathrm{v} 3$ signal processing scheme. Since small improvements were made to it in June 2006 , the primary validation period is taken as 1 July 2006-31 January 2007. Section 2 gives a brief description of the MST radar at Aberystwyth and describes the nature of both the desired clear-air and the unwanted radar return signals. Sections 3 and 4 give overviews of how the v0 and v3 schemes, respectively, have been designed to avoid contamination from the unwanted signal components. Section 5 focuses on how the v3 scheme exploits the complementarybeam information in order to maximise both data coverage and horizontal wind component accuracy. Section 6 examines the accuracy of the $\mathrm{v} 3$ wind-profile data by three separate methods. Finally, Sect. 7 discusses the implications of this work for optimising DBS observation formats for both operational and research purposes. 


\section{The MST radar at Aberystwyth}

The Aberystwyth MST radar operates at $46.5 \mathrm{MHz}$. The antenna consists of a 20 by 20 array of four-element Yagi aerials at 0.85 wavelength spacing, i.e. giving it side lengths of $104.1 \mathrm{~m}$. It is located at $50 \mathrm{~m}$ above mean sea level. The beam has a one-way half-power half-width of $1.5^{\circ}$. The radar has a peak transmitter power of $160 \mathrm{~kW}$ and a maximum duty cycle of $2.5 \%$. For each dwell during the primary validation period, the following observation parameters were used: an $8 \mu$ s transmitter pulse with a $2 \mu$ s complementary code baud length (i.e. giving a range resolution of $300 \mathrm{~m}$ ), a $320 \mu \mathrm{s}$ inter-pulse period, sampling of the receiver signal at $1 \mu \mathrm{s}$ intervals (i.e. at $150 \mathrm{~m}$, irrespective of the range resolution used) between ranges of 1.65 and $20.85 \mathrm{~km}$ from the radar, 512 point coherent integration, a Rectangular data weighting window (this was the only option available with the data acquisition system used at the time of the test), and a Discrete Fourier Transform (DFT) length of 128 points. This gives radar return Doppler power spectra with a Nyquist velocity of $9.84 \mathrm{~m} \mathrm{~s}^{-1}$ and a resolution of $0.15 \mathrm{~m} \mathrm{~s}^{-1}$. In this paper, a positive value of Doppler velocity will imply motion away from the radar. The acquisition duration for each dwell is approximately $21 \mathrm{~s}$. There is an approximately $2 \mathrm{~s}$ delay between the end of one dwell and the beginning of the next to allow for beam steering. The power spectral density (PSD) of the zero-Doppler-velocity velocity bin is replaced with a value linearly interpolated between those to either side. This is to remove contamination from dc biases in the in-phase and quadrature receiver samples (e.g. Hooper, 1999).

Off-vertical beam-pointing directions are referred to by their nominal azimuths (which are $-17.5^{\circ}$ with respect to the actual values so that $\mathrm{NE}$ refers to an azimuth of $27.5^{\circ}$ ) and by their zenith angles. During the primary validation period, observations were cycled through the following enhanced five-beam sequence: NE6.0, Vertical, SW6.0, Vertical, SE6.0, Vertical, NW6.0, Vertical, W4.2, Vertical, Mesospheric, Vertical. A single vertically-pointing mesospheric observation is included towards the end of the cycle (Hooper and Astin, 2007). This will not be considered any further in this paper. The ratio of the radar return signal powers observed at $4.2^{\circ}$ and $6.0^{\circ}$ off-vertical is used to compensate the magnitude of the horizontal wind components for the effects of aspect sensitivity (Thomas et al., 1997). This is applied by both the $\mathrm{v} 0$ and $\mathrm{v} 3$ schemes. Vertical beam observations are made every other dwell so that profiles of the vertical wind are available at regular intervals of approximately $47 \mathrm{~s}$. This feature was introduced in order to study the rapidly-varying vertical velocities associated with convection (Hooper et al., 2005). Nevertheless, as will be discussed in Sect. 7, this is a desirable feature of a regular wind-profiling scheme. Attention is drawn to the fact that each pair of complementarybeam observations are grouped together, separated by a vertical beam observation, within a period of $1 \mathrm{~min} 11 \mathrm{~s}$. A full cycle of observations takes $4 \min 43 \mathrm{~s}$.

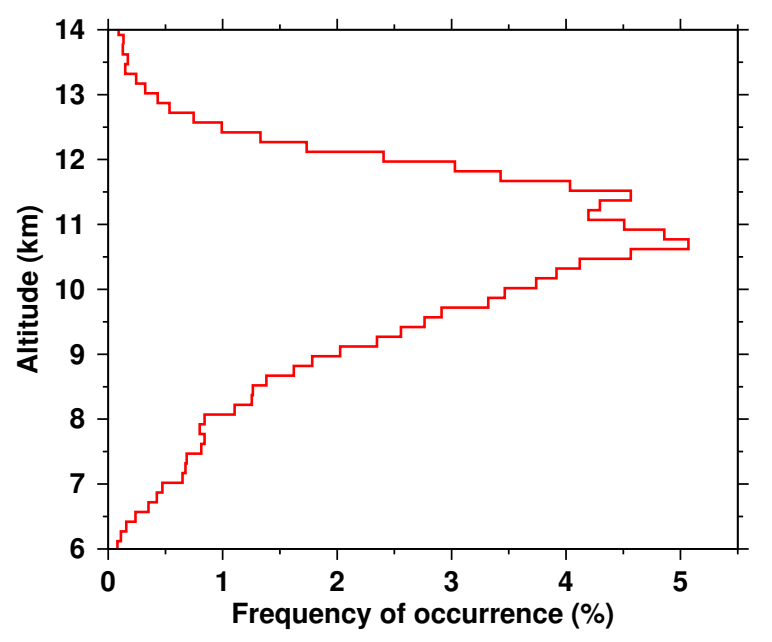

Fig. 1. Probability distribution of tropopause altitudes, in $150 \mathrm{~m}$ bins, derived from the radar return signal power of the first vertical beam observation of each observation cycle during the primary validation period.

Figure 1 shows the probability distribution of tropopause altitudes, derived from the radar return signal power using the objective method of Hooper and Arvelius (2000), for the primary validation period. This indicates that the tropopause lies predominantly between altitudes of 8.0 and $12.5 \mathrm{~km}$. The clear-air radar return signal power generally decreases with increasing altitude throughout the troposphere, increases at the tropopause, and then continues to decrease with increasing altitude thereafter. When the tropopause altitude lies above $10 \mathrm{~km}$, it is generally not possible to detect clear-air radar return signals in the uppermost troposphere for observations made at $6.0^{\circ}$ off-vertical. The extent of such a gap in useful altitude coverage also depends on the water vapour field in the uppermost troposphere (e.g. Hooper et al., 2004). The maximum useful altitude at which clear-air returns can be detected in the lower stratosphere is primarily determined by the profile of vertical temperature gradient. It is typically between 15 and $20 \mathrm{~km}$ for observations made at $6.0^{\circ}$ offvertical. This altitude can vary by several $\mathrm{km}$ over time scales of just a few hours. For vertical beam observations, clear-air radar returns are typically detectable over the entire altitude range.

Horizontal wind speeds above Aberystwyth tend to be several tens of $\mathrm{m} \mathrm{s}^{-1}-$ see Fig. 10. They can drop close to zero over a broad altitude range under high pressure conditions. Alternatively they can rise to $90 \mathrm{~m} \mathrm{~s}^{-1}$ within a jet stream in the uppermost troposphere. For most of the time, vertical wind magnitudes are of the order of $0.1 \mathrm{~m} \mathrm{~s}^{-1}$. However, mountain wave activity is common at Aberystwyth (e.g. Röttger, 2000) and gives rise to magnitudes of up to a few $\mathrm{m} \mathrm{s}^{-1}$. From Eq. (1) it can be seen that the relative contributions of the horizontal and vertical wind components to 

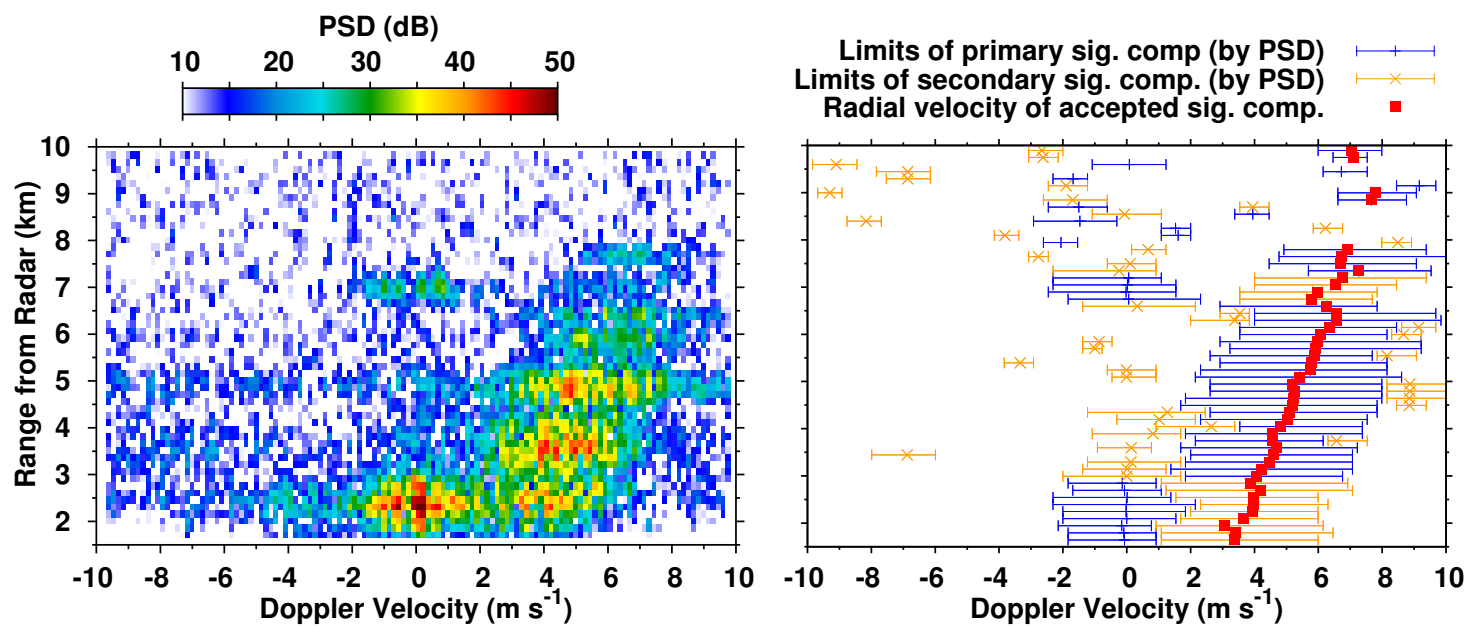

Fig. 2. Radar return Doppler spectra (left panel) and v3 signal component limits (right panel) for SE6.0 beam observations made at 07:06:56 UT on 18 January 2007. The spectra are contaminated by ground clutter. Doppler velocity extents are shown for the primary (blue lines) and secondary (orange lines) signal components by peak smoothed PSD. The red dots show the radial velocities of the signal components accepted for the clear-air profile by the radial-continuity algorithm.

radial velocity are weighted by $\sin \theta$ and $\cos \theta$, respectively. This is approximately $1: 10$ for observations made at $6.0^{\circ}$ offvertical. Consequently under conditions of mountain wave activity, the horizontal and vertical wind components will contribute comparable magnitudes to the off-vertical beam radial velocities. The design of a signal processing scheme needs to take into account the nature not only of the desired clear-air radar returns but of the three principal sources of unwanted signal components: ground clutter, interference, and Rayleigh scatter from hydrometeors under stratiform conditions.

The clear-air radar return signal components in the SE6.0 beam spectra shown in the left-hand panel of Fig. 2 are those with peak PSDs in the Doppler velocity range +3 to $+7 \mathrm{~m} \mathrm{~s}^{-1}$. The unwanted signal components, which are centred around a Doppler velocity of zero, are attributed to ground clutter (e.g. Cornman et al., 1998). This form of contamination at Aberystwyth is only seen in observations made by offvertical beams and is associated exclusively with strong lowlevel winds. Consequently the unwanted signal components tend to persist for anywhere between several hours and several days at a time. During an exceptional period between the beginning of January and the end of March 2005, ground clutter was seen for more than $50 \%$ of the time. The surface wind speed, recorded from a $10 \mathrm{~m}$ tower located $3 \mathrm{~km}$ to the west of the radar site, was in excess of $10 \mathrm{~m} \mathrm{~s}^{-1}$ at the time of the observations shown in Fig. 2. It is emphasised that this problem is distinct from the dc bias described in Sect. 2 in that it is spread across several velocity bins. Ground clutter observed by other radars can extend across a wide range of altitudes. However, at Aberystwyth it is confined to specific range gates, notably those just below $2 \mathrm{~km}$, those around
$3 \mathrm{~km}$, those around $7 \mathrm{~km}$, and sometimes those around $10 \mathrm{~km}$. Occasionally, as in this example, the lower two range gate bands merge into a single broader band. These ground clutter signal components tend to be stronger, in terms of peak PSD, than the clear-air signal components at most of the range gates where they are seen.

The interference signal components are those seen between Doppler velocity limits of -8.5 and $-6.5 \mathrm{~m} \mathrm{~s}^{-1}$ in the left-hand panel of Fig. 3 (cf. Morse et al., 2002). The Doppler velocity limits and the signal powers change very little from one range gate to the next. The peak PSDs tend to exceed those of the clear-air signal components only at the higher range gates. Each episode of interference tends to last between tens of minutes and several hours. During this time, the Doppler velocity limits remain relatively stationary for each of the beam-pointing directions affected. Interference can affect any beam-pointing direction, although it tends to be confined to only one or two of them during any one episode. The Doppler velocity limits of the interference signal components vary from one episode to the next. The Aberystwyth MST radar has always suffered from sporadic episodes of interference. It is suspected that these are primarily caused by overheating in the receiver equipment. It became a particularly common and severe problem between April and October 2006, apparently as a result of several pieces of previously free-standing equipment being installed into a single rack. The installation, in early 2007, of a continuously-operated air-conditioning unit has reduced the frequency of the problem to pre-2006 levels.

For observations made at frequencies around 400 and $1000 \mathrm{MHz}$, the radar return signal power caused by Rayleigh scatter from hydrometeors is expected to exceed that from 

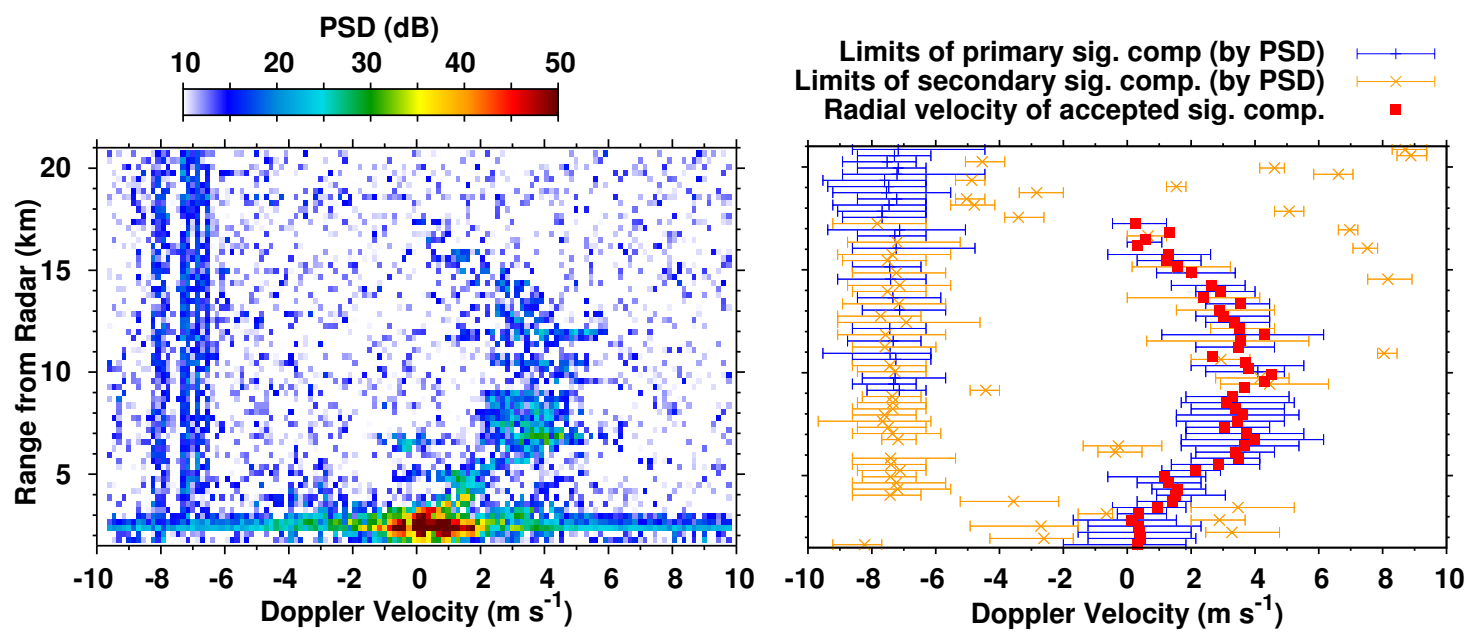

Fig. 3. As for Fig. 2 but for SE6.0 beam observations made at 22:54:30 UT on 25 September 2006 when interference occurred.

clear-air echoes. This is true even under conditions of very light precipitation (e.g. Ralph, 1995; Williams et al., 1995). Such signals are not considered a form of contamination at these frequencies. Indeed, the presence of hydrometeors can significantly increase the altitude coverage of wind-profilers operating at frequencies of around $1000 \mathrm{MHz}$. The strength of Rayleigh scatter is dependent on the minus fourth power of the radar wavelength. Consequently it is only expected to exceed that of clear-air echoes, for observations made at frequencies of around $50 \mathrm{MHz}$, if the precipitation rate exceeds $5 \mathrm{~mm} \mathrm{~h}^{-1}$ (e.g. Fukao et al., 1985; Larsen and Röttger, 1987; Lucas et al., 2004). This is consistent with convective rather than stratiform conditions. Nevertheless, even under stratiform precipitation conditions, i.e. rain rates of the around $1 \mathrm{~mm} \mathrm{~h}^{-1}$, lower-VHF radar observations have been able to detect weak Rayleigh scatter signals at tropical locations (e.g. May and Rajopadhyaya, 1996; Narayana Rao et al., 1999).

Owing to the fact that the fall speeds of snow flakes and the vertical winds are both small under stratiform precipitation conditions, the signal components can be difficult to distinguish at altitudes above the $0^{\circ} \mathrm{C}$ isotherm. However, below this the snow flakes melt and the resulting rain drops accelerate rapidly downwards. This gives rise to a Doppler velocity separation between the peaks of the two signal components. The signal power of the hydrometeor returns is typically smaller than that of clear-air returns except, perhaps, within a narrow bright-band region around the $0^{\circ} \mathrm{C}$ isotherm (e.g. Narayana Rao et al., 1999). This is caused by the partial melting of ice-crystals, which results in them becoming coated with water and hence increases their reflectivity.

As can be seen from the vertical beam spectra in the left-hand panel of Fig. 4, similar patterns can be seen at Aberystwyth under stratiform precipitation conditions. The level of the $0^{\circ} \mathrm{C}$ isotherm has been determined from a radiosonde launched at Camborne, which is $270 \mathrm{~km}$ to the south of Aberystwyth. The Rayleigh scatter signal components are those characterised by the most negative Doppler velocities at altitudes below this. Fall speeds of up to a few $\mathrm{m} \mathrm{s}^{-1}$ are common at the lowest range gates observed by the radar. Similar patterns are seen by all beam-pointing directions. The tipping bucket range gauge at the radar site, which records a tip for each $0.2 \mathrm{~mm}$ accumulation of rain, indicated a $10 \mathrm{~min}$ mean rain rate of $1.2 \mathrm{~mm} \mathrm{~h}^{-1}$ (i.e. the minimum detectable) during this period. The surprise here (Hooper and McDonald, 2007) is that the strength of the Rayleigh scatter signals, for such a low rain rate, can exceed that of the clear-air signals at altitudes significantly below the $0^{\circ} \mathrm{C}$ isotherm (cf. Larsen and Röttger, 1987; Ralph, 1995; Lucas et al., 2004). This can be explained by the fact that the clearair radar return power is significantly reduced below that expected from standard models under conditions of precipitation (e.g. Vaughan and Worthington, 2000).

Stratiform precipitation is the most common type falling over the British Isles. Each episode tends to last for several hours at a time. An analysis of all twice-daily Camborne radiosonde temperature profiles between 2003 and 2006 (not shown) indicates that the altitude of the $0^{\circ} \mathrm{C}$ isotherm is always below $5 \mathrm{~km}$. In $73 \%$ of cases it is above $1.7 \mathrm{~km}$, the altitude of the lowest range gate observed by the Aberystwyth MST radar. Consequently this form of contamination is observed often enough to require special attention.

Deep convection is seen sporadically at Aberystwyth in episodes which tend to last for the order of half an hour (e.g. Hooper et al., 2005). The associated rain rates are greater than $5 \mathrm{~mm} \mathrm{~h}^{-1}$ and the hydrometeor fall speeds can reach almost $10 \mathrm{~m} \mathrm{~s}^{-1}$ at the lowest observable altitudes. The hydrometeor returns dominate the clear-air returns under such conditions. However, as will be seen later, it is the nature of the clear-air radar returns which pose a more serious problem for wind-profiling. Updrafts and downdrafts can be as large 

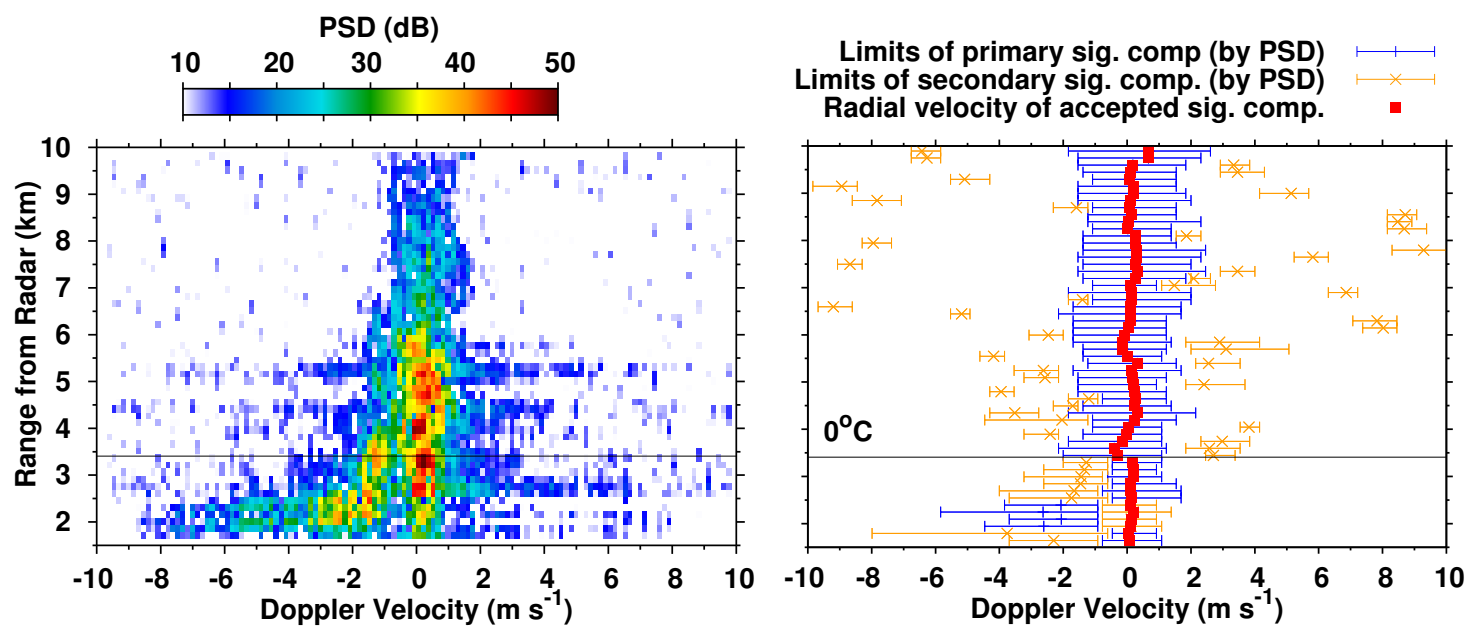

Fig. 4. As for Fig. 2 but for vertical beam observations made at 08:42:17 UT on 25 October 2006 when hydrometeor returns were observed during a stratiform precipitation event. The altitude of the $0^{\circ} \mathrm{C}$ isotherm is determined from a radiosonde launched at 11:00 UT on the same day from Camborne, which is located $270 \mathrm{~km}$ to the south of MST radar site. The two sites are more often than not located within the same air mass and so the Camborne measurements of temperature and of pressure (and, to a much lesser extent, of relative humidity) tend to be broadly representative of the atmosphere above the MST radar.

as $10 \mathrm{~m} \mathrm{~s}^{-1}$ and can change by more than $1 \mathrm{~m} \mathrm{~s}^{-1}$ in under a minute.

\section{An overview of the v0 scheme}

The simplest way to identify a signal component is to assume that it is responsible for the peak PSD within a spectrum. Its Doppler velocity limits can be established to either side of the peak location where a smoothed PSD envelope first drops below the noise PSD. The latter can be evaluated using an objective algorithm such as that of Hildebrand and Sekhon (1974). The spectra may first be extended, by selfmirroring about the Nyquist velocity at either end (e.g. Barth et al., 1994). This allows the appropriate signal limits to be determined even where partial velocity aliasing occurs. The three lowest-order moments - from which the signal power, radial velocity and spectral width are calculated (Woodman and Guillen, 1974) - are then evaluated within these signal limits. If no clear-air signal component is detectable, this technique will identify a random section of the spectrum, where a small noise fluctuation is most prominent above the mean noise PSD.

The simplest form of quality-control is to accept all signal components whose signal-to-noise ratio (or power or peak PSD) exceeds a given threshold. However, this is prone to accepting unwanted signal components, such as those seen in the previous section, where they are stronger than any clearair radar returns present. A more effective quality-control scheme relies on the fact that there is a high degree of correlation between wind vectors which are closely separated in time or in altitude (e.g. Weber et al., 1993). For a given dwell, a radial-continuity algorithm can be applied to test how well the radial velocity is matched for signal components at adjacent range gates. For a given range gate (and beam-pointing direction), a time-continuity algorithm can be applied to test how well the radial velocity is matched for signal components at adjacent cycles. Although such a scheme can be effective at removing unwanted signal components, this can lead to persistent data gaps if the source of these components is long-lived. This is unlikely to be a problem for an operational system. However, it is less desirable where the data are being used for research purposes. A more advanced scheme requires the identification of multiple signal components within each spectrum (e.g. Clothiaux et al., 1994; Griesser and Richner, 1998). This allows a second choice of signal component if the strongest one fails the radial- or time-continuity tests.

Figure 5 shows a simplified block diagram of the v0 signal processing scheme. It can be seen that the level of complexity lies somewhere between the simplest and most advanced scenarios described above. Although only a single signal component is identified within each spectrum, this is not necessarily the strongest one. After selecting the strongest signal component at the lowest range gate, a radial-continuity algorithm restricts the Doppler velocity limits within which a peak PSD location may be identified at the next highest range gate. This search pattern is repeated at all subsequent range gates upwards through the profile. Although it is highly effective at avoiding unwanted signal components which are clearly distinct from the clear-air components - such as the clutter components seen at altitudes of around $7 \mathrm{~km}$ in the left panel of Fig. 2 and the interference components seen at 


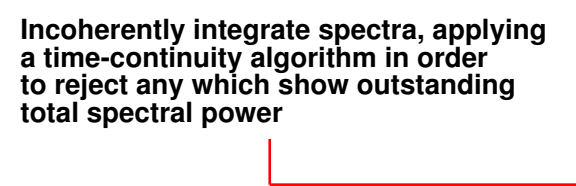

ALL DWELLS FOR A GIVEN BEAM POINTING DIRECTION WITHIN A GIVEN TIME INTERVAL

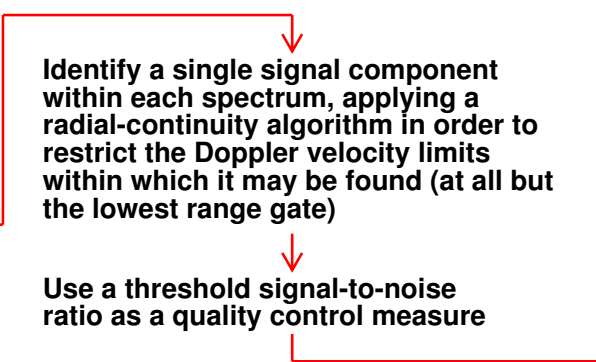

SINGLE AVERAGED DWELL

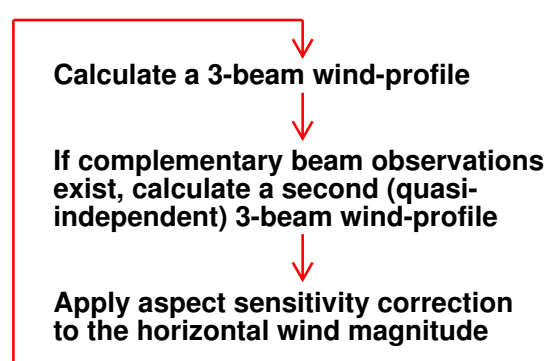

SINGLE AVERAGED CYCLE

Fig. 5. A simplified block diagram of the v0 signal processing scheme.

all altitudes in Fig. 3 - the v0 scheme is not able to resolve partially-overlapping unwanted and clear-air signal components - such as those seen at altitudes below $3.0 \mathrm{~km}$ in Fig. 2 and those seen at altitudes below $3.5 \mathrm{~km}$ in Fig. 4 . In these cases, the PSDs between the peaks of the two signal components do not drop to below the noise PSD. Consequently they are identified as belonging to a single, broad signal component (cf. Wilczak et al., 1995).

Although it is not common for clear-air and ground clutter signal components to overlap in the way seen below $3 \mathrm{~km}$ in Fig. 2, it is always the case for clear-air and Rayleigh scatter signals under stratiform conditions. The radial velocities derived by the v0 scheme for altitudes below $3.5 \mathrm{~km}$ in Fig. 4 correspond, approximately, to the locations of the minima between the two peaks. They become increasingly negative with decreasing altitude, reaching approximately $-1 \mathrm{~m} \mathrm{~s}^{-1}$ at the lowest range gates. Owing to the fact that these combined signal components show both radial and time continuity, they are not rejected by the quality-control procedures. This form of contamination leads to errors in both the vertical and horizontal wind components in episodes which typically last several hours.

The v0 scheme makes use of a time-continuity algorithm, which was designed specifically to avoid contamination from aircraft echoes. Aircraft are typically seen through the sidelobes of the radar beam and so their horizontal motion translates into rapid changes in range as a function of time. Consequently they are not expected to be seen at the same range gates by the same beam-pointing direction from one cycle to the next, i.e. with a time separation of a few minutes. The v0 scheme rejects any spectra whose total power is significantly different to that of their nearest neighbours in time. Although this is effective, the signal components which pass the time-continuity test are subsequently time-averaged in an unconventional, and a not entirely desirable, way.

Time-averaging of spectra, known as incoherent integration, is typically performed on data acquired for contiguous time slots. The v0 scheme applies it by averaging spectra (for the same beam-pointing direction and the same range gate) which are each separated from the next by a whole cycle, i.e. by a few minutes. Both the time-continuity algorithm and the time-averaging of spectra are carried out over 3 cycles of observation, which corresponds to just over $14 \mathrm{~min}$. The radial velocities are derived for signal components identified within these incoherently-integrated spectra before being combined with those for the other beam-pointing directions in order to give the three dimensional wind vector. This is somewhat similar to deriving the radial velocities for signal components identified within unaveraged spectra, then averaging the radial velocities separately for each each pointing direction, and then combining these with those for the other beam pointing directions (e.g. Weber et al., 1992). Both methods are acceptable when the vertical wind shows negligible variations over the averaging period. However, this is not the case under conditions of short-period gravity wave activity, which is principally generated by convection (e.g. Hauf, 1993) or by flow over orography (e.g. Röttger, 2000).

The atmosphere can support gravity waves which range in period from the Brunt-Väisälä period - approximately $10 \mathrm{~min}$ in the troposphere and $5 \mathrm{~min}$ in the lower stratosphere (e.g. Hooper et al., 2004) - up to the inertial period, which is approximately $15 \mathrm{~h}$ at the latitude $\left(52.4^{\circ} \mathrm{N}\right)$ of Aberystwyth. For waves with periods of less than one hour, the oscillations are primarily in the vertical direction. Under quiet conditions, i.e. characterised by vertical wind magnitudes of the order of $0.1 \mathrm{~m} \mathrm{~s}^{-1}$, radar-derived vertical-velocity frequencyspectra tend to show a small peak in PSD at the Brunt-Väisälä period, approximately constant values at longer periods, and a sharp reduction in value at shorter periods (e.g. Ecklund et al., 1985). Consequently any variability of the vertical wind during the course of one, or even of several, cycles will be of insignificant amplitude.

Under conditions of mountain wave activity, i.e. characterised by vertical wind magnitudes of the order of $1 \mathrm{~m} \mathrm{~s}^{-1}$, there is no peak in PSD at the Brunt-Väisälä period. Instead the PSDs show an approximately $f^{-5 / 3}$ dependence, 
where $f$ is the wave frequency, at periods of between 10 and $100 \mathrm{~min}$. Moreover, they do not do not fall off rapidly at periods of less than the Brunt-Väisälä period and can be nearly two orders of magnitude greater in the $2-3$ min period range than under quiet conditions (Ecklund et al., 1985). Refer to Worthington and Thomas (1998), and references therein, for a discussion as to why the power from apparently monochromatic waves should be spread across a wide range of frequencies when observed by a ground-based instrument. Under mountain wave conditions, the vertical wind can be expected to change significantly not only from one cycle to the next, put possibly even during the course of a single cycle. This latter condition, which will lead to a violation of the fundamental DBS assumption of a stationary wind field, will be discussed in more detail in Sect. 5. At this stage, it is sufficient to say that v0-derived (14 min) time-averaged horizontal wind components can sometimes show unrealistic modulations, which are not seen in the v3 data and which are clearly related to vertical wind variations. However, this is not always the case as the form of mountain wave activity is quite variable.

\section{An overview of the v3 scheme}

Figure 6 shows a simplified block diagram of the v3 signal processing scheme. This level of complexity was necessitated by the nature of the unwanted signal components described in Sect. 2. The v1 and v2 pre-cursors to the v3 scheme identified only a single signal component (the strongest) within each spectrum and relied on a timecontinuity algorithm for quality-control purposes. The lack of a radial-continuity algorithm made them prone to contamination from ground clutter and interference. Both types of signal component tend to be stronger than the corresponding clear-air returns and they show a high degree of timecontinuity (cf. Wuertz et al., 1988). However, a more fundamental requirement for the v3 scheme was the ability to resolve partially-overlapping clear-air and unwanted signal components. This is achieved by defining a signal component Doppler velocity limit where the (five bin) smoothed PSD envelope encounters a local minimum (cf. Narayana Rao et al., 1999; Lucas et al., 2004) which is at least $10 \mathrm{~dB}$ below the peak smoothed PSD.

A signal component limit can also be identified where the smoothed PSD drops to below $-20 \mathrm{~dB}$ relative to the peak smoothed PSD, if this is reached before the noise PSD is crossed. This third criterion accounts for the fact that the original data acquisition system allowed only a Rectangular window to be used, for weighting the coherently-integrated in-phase and quadrature samples, prior to applying a DFT. Spectral leakage through the sidelobes of this window becomes apparent for peak signal PSDs more than approximately $20 \mathrm{~dB}$ above the noise level (Harris, 1978). This leads to, amongst other things, a broadening of the Doppler veloc- ity limits within which the smoothed PSD is above the noise level (e.g. Hooper, 1999). Although this has a negligible effect on the signal power and on the radial velocity, it can lead to a substantial overestimate of the spectral width. It is noted that the same truncation can be achieved by fitting a Gaussian curve to the observed signal envelope (e.g. Cohn et al., 2001).

The blue lines in the right hand panels of Figs. 2-4 show the Doppler velocity extent of the signal components associated with the peak (smoothed) PSD within each spectrum. The orange lines show the extent of the secondary signal components, which are associated with the strongest peak smoothed PSD outside of the primary limits. As can be seen, the simple method of resolving partially-overlapping signal components is highly effective. It is noted that some authors (e.g Narayana Rao et al., 1999; Lucas et al., 2004; McDonald et al., 2004) have used Gaussian curve fitting techniques in order to establish the principal signal parameters for partially-overlapping clear-air and hydrometeor signal components. Moreover, techniques exist for separating signal components which are fully-overlapping (e.g. Boyer et al., 2004). However, neither of these has been employed by the $\mathrm{v} 3$ scheme at the current time.

The radial continuity algorithm used by the v3 scheme is very similar to that described by Griesser and Richner (1998). However, the latter carries out both radial- and timecontinuity tests as part of the same procedure. The primary role of the v3 radial-continuity algorithm is to determine which one of the two signal components at each range gate is most likely to correspond to a clear-air radar return. Attention is restricted to these signal components in all subsequent processing. The algorithm begins by identifying radial chains, i.e. groups of signal components at contiguous range gates which are unambiguously connected. These are then joined together with other chains to form longer profiles. The combination of chains which encompasses the largest number of signal components is chosen as the basis for a clear-air return profile.

As can be seen in Fig. 3, interference signal components can lead to a higher degree of radial-continuity than clear-air signal components. Fortunately, a profile of interference signal components is easy to identify since the power changes very little from one signal component to the next. Clear-air signal components, by contrast, vary in power by several orders of magnitude over the altitude range $2-20 \mathrm{~km}$. Consequently, if the standard deviation of signal power within the longest (basis) profile is found to be less than $3 \mathrm{~dB}$, the next longest profile is tested for its suitability. Since ground clutter observed by the Aberystwyth MST radar is confined to limited range gates, there is no possibility of it causing the same problem. However, this can be an important consideration for other radars (e.g. Griesser and Richner, 1998). The (radial velocities of the) signal components identified as belonging to the clear-air profile are indicated by the red dots in the right hand panels of Figs. 2-4. 


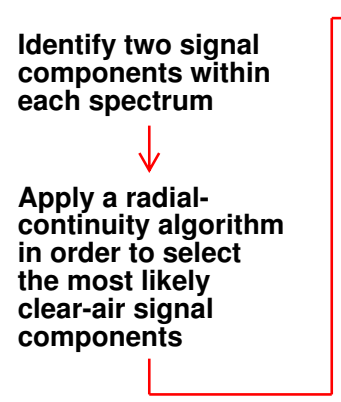

SINGLE DWELL

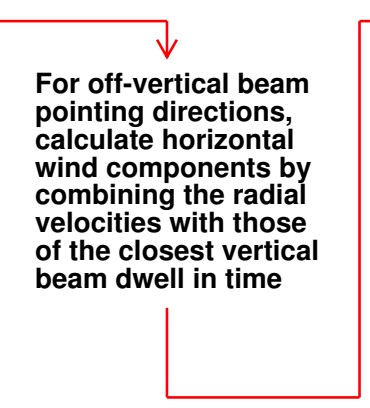

\begin{tabular}{|l|} 
\\
Apply a time- \\
continuity algorithm, \\
either to the vertical \\
or to the horizontal \\
wind components, \\
as a quality control \\
procedure
\end{tabular}

SINGLE CYCLE

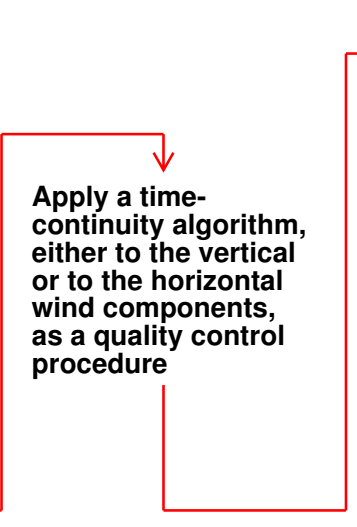
ALL DWELLS FOR
A GIVEN BEAM
POINTING DIRECTION
WITHIN A GIVEN TIME
INTERVAL

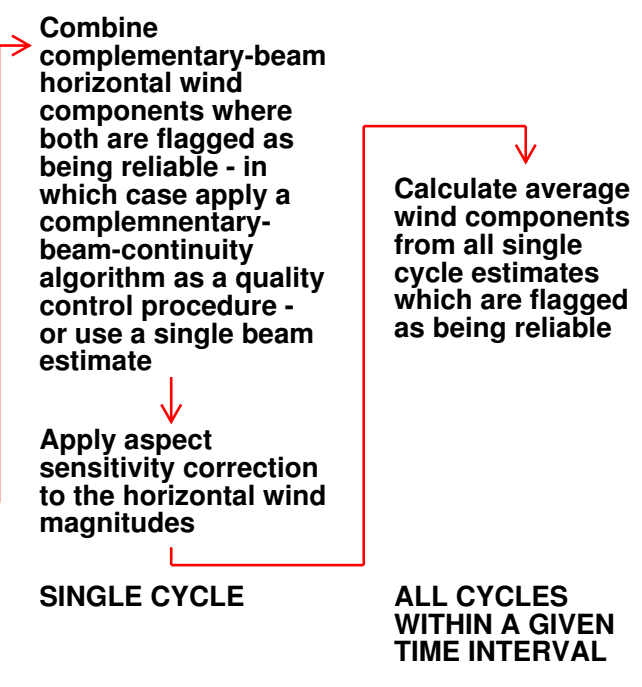

Fig. 6. A simplified block diagram of the v3 signal processing scheme.

It is noted that radial-continuity is not a sufficient basis for discriminating between the clear-air and Rayleigh scatter signal components seen below the $0^{\circ} \mathrm{C}$ isotherm. Additional work will be required in order to improve the v3 scheme's ability to select the clear-air component. A more detailed discussion of this topic is beyond the scope of the present manuscript.

The v3 scheme's time-continuity algorithm is based on the principles of consensus averaging, which is commonly applied to wind-profiler data (e.g. Barth et al., 1994). All signal components, for the same beam-pointing direction and for the same range gate, within a one hour interval are compared. It has already been mentioned that the vertical wind can change significantly over such an interval. Moreover the magnitude of its contributions to the radial velocities for offvertical beam observations can be comparable to that of the horizontal wind. Consequently the degree of variability of the radial velocities is potentially much larger than can realistically be attributed to changes in the horizontal wind vector. For this reason, the time-continuity algorithm is applied to the horizontal wind components for off-vertical beam observations (and the results of this test are attributed to the off-vertical beam signal component, despite the fact a vertical beam observation was also involved in deriving the horizontal wind component) and to the vertical wind components for vertical beam observations.

The time-continuity algorithm is applied twice. On the first occasion it is applied to all signal components within the hour prior to the time of the one being quality-controlled. This minimises the delay in producing quality-controlled data for operational assimilation. However, for data which are destined for off-line analysis, it is more desirable to con- sider all signal components within $30 \mathrm{~min}$ to either side of the one being quality-controlled. There are only slight differences between the results of these two implementations. Signal components must pass both radial- and time-continuity quality-control procedures in order to be considered further for deriving wind-profiles.

\section{Exploitation of complementary-beam information}

The availability of complementary off-vertical beam observations can be used to provide two quasi-independent estimates of the horizontal wind components (e.g. Strauch et al., 1987). This was done by the v0 scheme. However, it is more common to calculate the average of the two components, $v_{H C}(\phi)\left(\mathrm{m} \mathrm{s}^{-1}\right)$, taking the change of sign into account, i.e.:

$v_{H C}(\phi)=\frac{v_{H}(\phi)-v_{H}\left(\phi+180^{\circ}\right)}{2}$

This reduces the random error inherent in each individual estimate. The difference between the estimates (taking the change of sign into account) can be used to derive a complementary-beam-continuity factor, $\Delta v_{H C}(\phi)\left(\mathrm{m} \mathrm{s}^{-1}\right)$, which provides a measure of reliability:

$\Delta v_{H C}(\phi)=\left|v_{H}(\phi)+v_{H}\left(\phi+180^{\circ}\right)\right|$

It is noted that the averaged horizontal wind components can be derived simply by taking the difference between the radial velocities for a complementary-beam pair (e.g. Adachi et al., 2005), since, by substituting for $v_{R}$ from Eq. (1):

$v_{R}(\theta, \phi)-v_{R}\left(\theta, \phi+180^{\circ}\right)=2 v_{H}(\phi) \sin \theta$ 


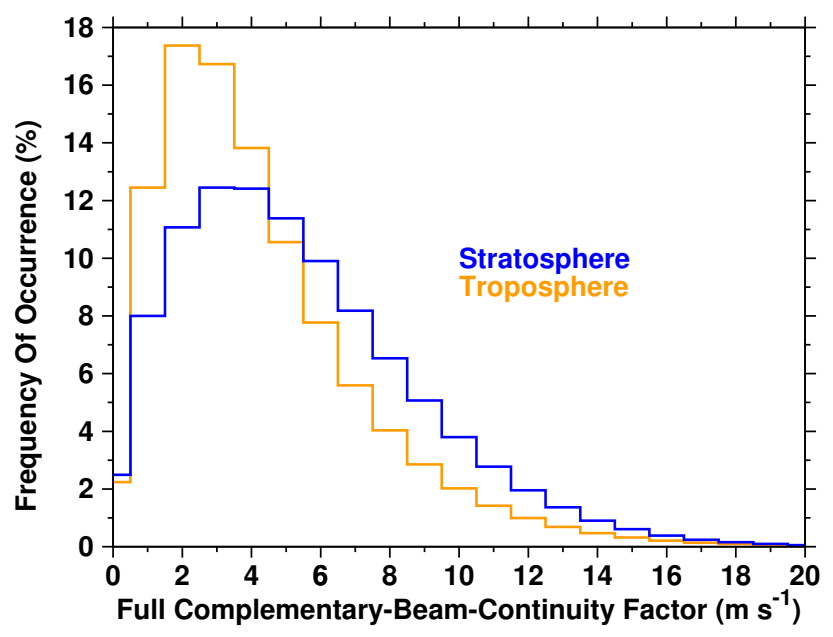

Fig. 7. The probability distribution of the full complementarybeam-continuity factor values, in $1.0 \mathrm{~m} \mathrm{~s}^{-1}$ bins, for tropospheric (orange line) and stratospheric (blue line) altitudes. Data are considered for the primary validation period.

This is directly equivalent to first calculating individual horizontal components and then averaging them since the $w \cos \theta$ terms for each value of $v_{H}$ cancel. Taking the sum of the radial velocities for a complementary-beam pair, in principle, gives a measure of the vertical velocity:

$v_{R}(\theta, \phi)+v_{R}\left(\theta, \phi+180^{\circ}\right)=2 w \cos \theta$

However, this assumes that the magnitude of the horizontal wind contributions for each of the complementary-beam observations is exactly equal. This would imply a $\Delta v_{H C}$ value of zero. A non-zero value of $\Delta v_{H C}$ would result if the wind vector changed significantly either over the spatial scale separating the complementary-beam observation volumes (i.e. approximately $2 \mathrm{~km}$ at an altitude of $10 \mathrm{~km}$ ) or over the temporal scale separating the dwells (i.e. $1 \mathrm{~min} 11 \mathrm{~s}$ ). Either of these is possible under conditions of short-period gravity wave activity.

Although the typical horizontal wavelengths of mountain waves, 10-30 km (e.g. Worthington, 1999), are much larger the separation between the radar observation volumes, those of convectively-generated gravity waves can be in the range $2.5-8.5 \mathrm{~km}$ (e.g. Hauf, 1993). Moreover, it has already been established that wave-driven vertical winds can change significantly within the time scale of just a few minutes. There are three reasons for expecting values of $\Delta v_{H C}$ to be greater in the lower-stratosphere than in the troposphere: gravity wave amplitudes increase with increasing altitude, the BruntVäisälä period is shorter (and therefore closer to the cycle time), and the radar observation volumes are further apart. However, it should be noted that gravity waves are not al- ways able to propagate upwards beyond the tropopause level (e.g. Worthington and Thomas, 1996a).

Figure 7 shows the probability distribution of the full complementary-beam-continuity factor, i.e. the root of the sum of the squares of the $\Delta v_{H C}(\phi)$ and $\Delta v_{H C}\left(\phi+90^{\circ}\right)$ values, for the primary validation period. Values have only be calculated where all four $6^{\circ}$ off-vertical signal components have individually passed the radial- and timecontinuity quality-control procedures. The distribution for the stratosphere (blue line) shows the expected shift towards larger values compared to that for the troposphere (orange line). The tropopause altitude is determined as described in Sect. 2. The reliability of the horizontal wind estimates associated with the larger values of the full complementarybeam-continuity factor must be doubted, even if individually the wind components appear to be reliable. For this reason, $v_{H C}(\phi)$ estimates are flagged as being unreliable if the corresponding values of $\Delta v_{H C}(\phi)$ are greater than $10.0 \mathrm{~m} \mathrm{~s}^{-1}$.

The use of $\Delta v_{H C}(\phi)$ for quality-control purposes was introduced in the v2 scheme as a way of dealing with contamination from ground clutter and interference. Neither of these types of signal component could be rejected on the basis of time-continuity alone (and the v2 scheme lacked a radial-continuity algorithm). However, at any one time, they do not tend to contaminate the observations made by both of the complementary beam-pointing directions. This gives rise to $\Delta v_{H C}(\phi)$ values of several $10 \mathrm{~s}$ of $\mathrm{m} \mathrm{s}^{-1}$. This technique was also found to be an effective way of rejecting the clearly-unreliable horizontal wind variations associated with convective activity. Although only clear-air signal components are involved, the associated changes in vertical wind can be more than $1 \mathrm{~m} \mathrm{~s}^{-1}$ in under a minute (Hooper et al., 2005). This clearly violates the fundamental DBS assumption of a stationary wind field. It should be noted that most of the signal components associated with convection are already rejected on the basis of failing the time-continuity test. Other authors (e.g. Worthington, 2004; Adachi et al., 2005; Ishihara et al., 2006) have reported inhomogeneities between the observations made in different beam pointing directions under convective conditions.

Based on the above experiences, it was anticipated that the distribution of full complementary-beam-continuity factor values would be mostly concentrated around zero, but with a small spread at much larger values. It was unexpected that the locations of the peaks of these distributions should be significantly non-zero and that the frequencies of occurrence should decrease so gradually at larger values. Although large values of $\Delta v_{H C}(\phi)$, i.e. $>10 \mathrm{~m} \mathrm{~s}^{-1}$, are often associated with short-period gravity waves, they are not correlated with the magnitude of the vertical wind (as determined from vertical beam observations). They can often be associated exclusively with the top of a region of mountain wave activity, i.e. where the wave is breaking (e.g. Worthington and Thomas, 1996a), or with the transition from troposphere to lower-stratosphere, which is accompanied be a reduction in 
vertical wavelength. They can also be associated with regions of large vertical shear of the horizontal wind, which are expected to be turbulent.

Despite the usefulness of the complementary-beamcontinuity factor as a final test of horizontal wind component reliability, attention should not be restricted to those range gates for which both of the individual complementary horizontal wind components have previously been flagged as being reliable. The green profile in Fig. 8 shows the frequency of NE wind component availability, as a function of altitude, based on the requirement that both the NE6.0 and SW6.0 signal components have been flagged as being reliable. As shown by the orange profile, significantly better availability is possible if only one of these signal components (in this case from the NE6.0 beam observations) is required to be reliable (the profiles for the SE6.0, SW6.0 and NW6.0 observations are very similar).

There can be significant imbalances between radar return signal power for complementary-beam observations. This can be caused by the tilting of isentropes by wave activity (e.g. Worthington and Thomas, 1996b; Worthington, 1999) or by Kelvin-Helmholtz instabilities (e.g. Muschinski, 1996). Consequently it is to be expected, particularly in regions of low signal-to-noise ratio, that a clear-air signal component may be seen in one of the complementary beam-pointing directions but not in the other. As can be seen from the blue profile in Fig. 8, horizontal wind component availability is maximised if the requirement is for only one or the other (or possibly both) of the signal components to be available.

The v3 scheme consequently adapts its exploitation of the complementary-beam information in response to the availability of individual components. If both complementarybeam horizontal wind components are available, they are averaged - and the complementary-beam-continuity factor is used for quality-control purposes. However, if only one of the individual horizontal wind components is available, that alone will be used. Only those horizontal wind components which have passed all quality-control tests are subsequently used to derive the $30 \mathrm{~min}$ averaged wind-profiles which are assimilated by the Met Office.

\section{Measures of v3 data accuracy}

Radiosondes are still the primary source of upper-air windprofiles. The quality of the data has been extensively examined and the error characteristics are well-known (e.g. Kitchen, 1989; Nash, 1994). Consequently the ideal method for evaluating the accuracy of Aberystwyth radar-derived wind-profiles would be to compare them against radiosonde data for launches from Aberporth $\left(52.13^{\circ} \mathrm{N}, 4.57^{\circ} \mathrm{W}\right)$, which is $45 \mathrm{~km} \mathrm{~km}$ to the south-west of the radar site $\left(52.40^{\circ} \mathrm{N}\right.$, $4.01^{\circ} \mathrm{W}$ ). Thomas et al. (1997) note that even such a small distance between radiosonde measurements can give rise to root mean square (RMS) differences of $3-4 \mathrm{~m} \mathrm{~s}^{-1}$. Although

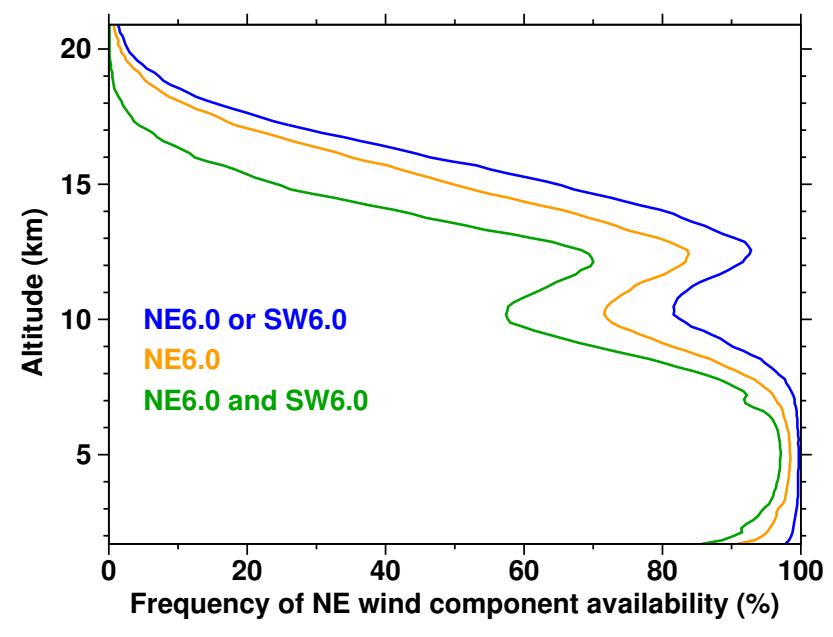

Fig. 8. Frequency of NE horizontal wind component availability, as a function of altitude, when just the NE6.0 beam derived components are considered (orange line), when both the NE6.0 and the SW6.0 derived components must be available (green line), and when either NE6.0 or the SW6.0 derived components are available (blue line). Data are taken from the primary validation period.

comparisons against radiosonde data were routinely made in the past (e.g. Thomas et al., 1997), Aberporth is not part of the (UK) Met Office's operational radiosonde network. Consequently wind-profile data are not available from there on a routine basis. No data at all were available for the primary validation period. The Met Office's principal method of evaluating radar-derived wind data quality is therefore by making comparisons against the short term forecast wind fields from the global run of the Unified Model (Dibbern et al., 2003a).

The Unified Model does not provide a perfect representation of the atmosphere. For example, it is known that wind component forecast errors can be larger than $2 \mathrm{~m} \mathrm{~s}^{-1}$ in the lower troposphere at mid-latitudes (Dibbern et al., 2003a). Moreover, the relative coarseness of the model's horizontal resolution (approximately $40 \mathrm{~km}$ at mid-latitudes) means that it is not able to represent some of the small-scale wind fluctuations observed by the radar. Consequently the modelcomparison statistics should not be regarded as representing solely the errors in the observations. Nevertheless the model fields provide a convenient common frame of reference against which all sources of assimilation data are compared. If two sources of data have similar model-comparison statistics, it can be inferred that their measurement accuracies are broadly comparable (Dibbern et al., 2003a).

Owing to the fact that the nearest operational radiosonde station is over $200 \mathrm{~km}$ away from the radar site, a composite of wind data from all radiosonde launch sites across the British Isles has been found to provide the most appropriate reference model-comparison statistics. These are shown by the blue lines in Fig. 9. The radiosonde 

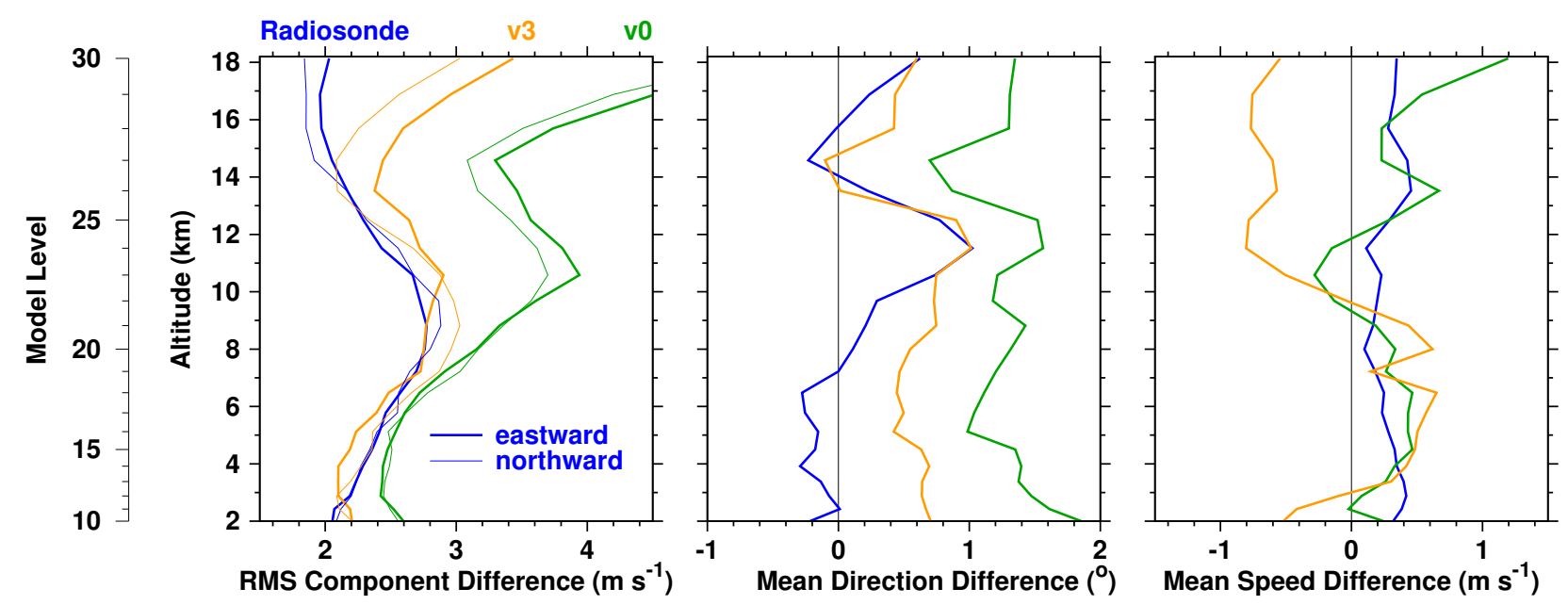

Fig. 9. Profiles of observed-model horizontal wind comparison statistics for radiosondes (blue lines), v0 data (green lines), and v3 data (orange lines) for the primary validation period. The leftmost panel shows the root mean square differences in eastward (thick lines) and northward (thin lines) components, the middle panel shows the mean differences in direction, and the rightmost panel shows the mean differences in speed.

stations are located at Lerwick $\left(60.13^{\circ} \mathrm{N}, 1.18^{\circ} \mathrm{W}\right)$, Albemarle $\left(55.02^{\circ} \mathrm{N}, 1.88^{\circ} \mathrm{W}\right)$, Castor Bay $\left(54.50^{\circ} \mathrm{N}, 6.33^{\circ} \mathrm{W}\right)$, Watnall $\left(53.02^{\circ} \mathrm{N}, 1.25^{\circ} \mathrm{W}\right)$, Valentia $\left(51.93^{\circ} \mathrm{N}, 10.25^{\circ} \mathrm{W}\right)$, Larkhill $\left(51.20^{\circ} \mathrm{N}, 1.82^{\circ} \mathrm{W}\right)$, Herstmonceux $\left(50.88^{\circ} \mathrm{N}\right.$, $\left.0.32^{\circ} \mathrm{E}\right)$, and Camborne $\left(50.22^{\circ} \mathrm{N}, 5.33^{\circ} \mathrm{W}\right)$.

The most important of the model-comparison statistics is the RMS difference between the observed and the model wind components, shown in the left-hand panel of Fig. 9. This represents a combination of both systematic and random errors (Dibbern et al., 2003a). As mentioned above, the fact that the values for radiosondes (blue lines) and for v0 radar data (green lines) are so similar, at altitudes below $8 \mathrm{~km}$, suggests that the accuracies of the two techniques are broadly comparable. The deviation between the two sets of profiles at higher altitudes is a consequence of the v0 scheme's relatively simplistic quality-control techniques. Although the radial-continuity algorithm is effective at avoiding unwanted signal components where strong clear-air signal components exist, it is less effective at quality-controlling potential signal components in regions of low signal-to-noise ratio. Since the time-continuity algorithm is designed solely to avoid contamination from aircraft returns, many random noise fluctuations are accepted as being reliable signals at the higher range gates.

The orange lines in Fig. 9 demonstrate that significantly improved accuracy is possible at all altitudes using data from the v3 scheme. The quality of the v3 data is almost indistinguishable from that of radiosonde data right the way up to an altitude of $14 \mathrm{~km}$. Although there is a slight reduction in data quality at the higher range gates, this is not as dramatic as that associated with the $\mathrm{v} 0$ scheme. The mean of the (observed - model) direction values, shown in the middle panel, indicates that the $\mathrm{v} 3$ scheme also leads to a slight reduction in systematic directional bias (to less than $1^{\circ}$ ) compared with that of the v0 scheme. Although, as shown in the right-hand panel, there is a systematic overestimate of v3 wind speed at altitudes below $10 \mathrm{~km}$, and a systematic underestimate at higher altitudes, the magnitude of these errors $\left(<1 \mathrm{~m} \mathrm{~s}^{-1}\right)$ is too small to be of particular concern.

Although Aberporth radiosonde data were not available for the primary validation period, data for 147 launches are available for the period June-December 2007. The production of v0 data ceased in February 2007 and so it is only possible to compare wind speeds from radiosondes with those derived from the $\mathrm{v} 3$ scheme. These data are only shown in Fig 10 where samples for both instruments are available. The $\mathrm{v} 3$ data have been averaged over $1 \mathrm{~h}$ (the approximate time taken for a radiosonde to reach an altitude of $20 \mathrm{~km}$ ) starting from the time of the radiosonde launch. This plot has fewer, and less significant, outliers than the equivalent Fig. 3 shown by Thomas et al. (1997) for the v0 scheme.

The best fit between these data is found by the method of Hocking et al. (2001). The regression lines, shown in blue, correspond to the assumptions that all of the errors are associated with the radiosonde measurements (which gives rise to a gradient of 0.939) and that all are associated with the radar measurements (which gives rise to a gradient of 1.018). The 258 data points shown in green were excluded from this analysis by iteratively removing all data points which lay more than 3 standard deviations from an intermediate fit. This leaves 9178 data points. Assuming that the measurement errors are distributed equally between the radar and the radiosonde data, the best fit line has a gradient of 0.959 . The magnitude of the measurement errors is represented by 


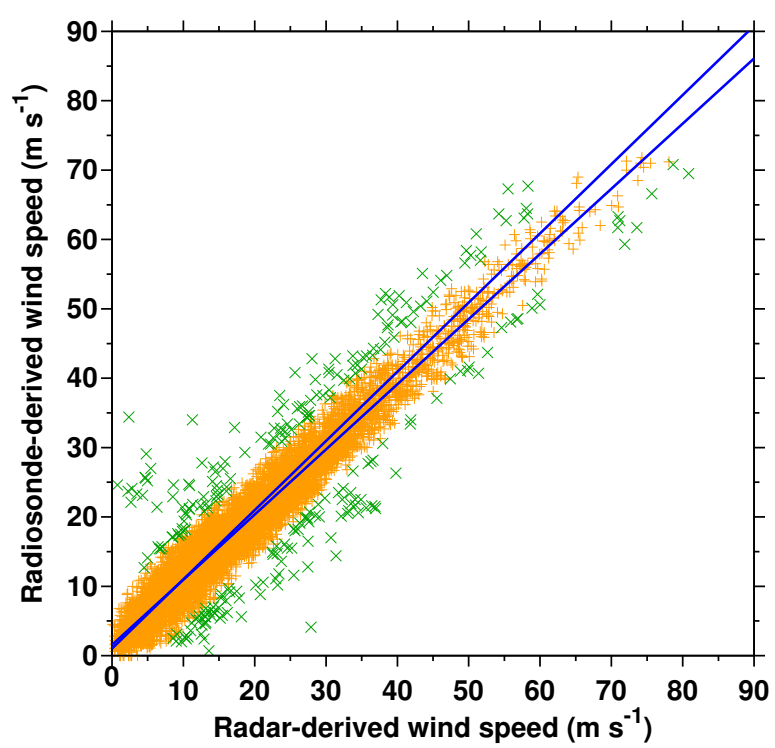

Fig. 10. Scatter plot of radiosonde- and v3 radar-derived wind speeds for 147 radiosondes launched between July and December 2007. The 258 points shown in green were removed before performing a regression analysis on the remaining 9178 data points shown in orange. The two blue lines show the best fits for the regression of $y$ on $x$ and of $x$ on $y$ following the method of Hocking et al. (2001).

a standard deviation of $1.64 \mathrm{~m} \mathrm{~s}^{-1}$. This value, in part, represents the degree of atmospheric variability over the spatial scale separating the two measurements and the difference between the way in which the measurements are made (Hocking et al., 2001).

A final method of evaluating v3 data quality is to carry out a self-consistency test. A commonly-used technique is to calculate the RMS differences between velocity components at adjacent time steps (e.g. Dibbern et al., 2003a). This is only done where the wind components at both time steps are flagged as being reliable. The values represent a combination of random measurement errors and of the degree of atmospheric variability over the time scale between the measurements. The values of $3.0-4.0 \mathrm{~m} \mathrm{~s}^{-1}$ for the single cycle horizontal wind components, i.e. those available at intervals of $4 \mathrm{~min} 43 \mathrm{~s}$, are shown by the orange profile in the left-hand panel of Fig. 11. The profiles for the eastward and northward components are very similar and so only the former is shown. The horizontal wind components are expected to show a low degree of natural variability over such a short time scale. Consequently the RMS difference values largely represent the random measurement error.

Kitchen (1989) has shown that the RMS differences between radiosonde wind measurements (for a single station) increase with increasing time difference between the launches. This is consistent with observations made by windprofiling radars. The frequency spectra of horizontal-wind

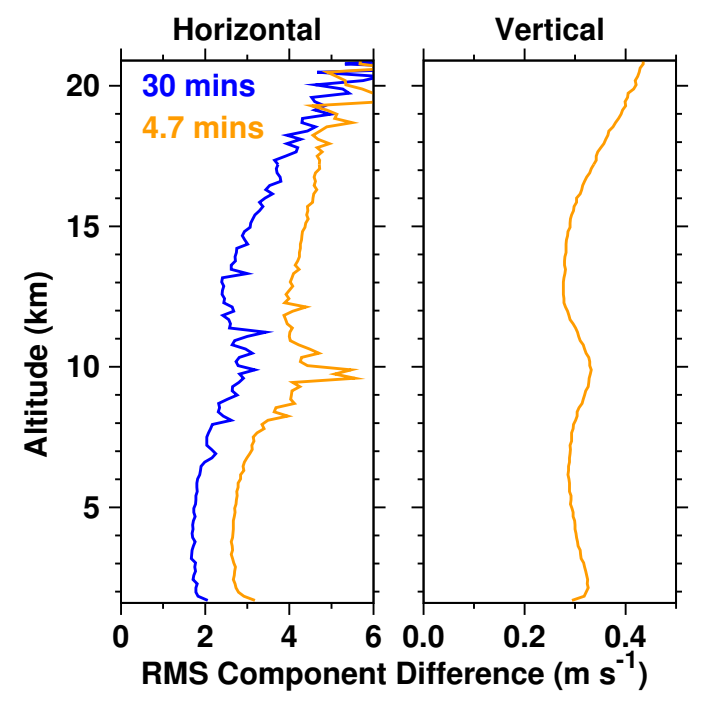

Fig. 11. Profiles of the root mean square differences between v3 wind components at adjacent cycles (orange lines) and at adjacent 30 min average messages (blue line). The left panel shows the profiles for the eastward wind component and the right panel shows the profiles for the upward wind component. Data are considered for the primary validation period.

fluctuations typically show an $f^{-5 / 3}$ dependence, where $f$ is the frequency (e.g. Gage and Nastrom, 1985). Therefore a greater degree of natural variability is expected between the $30 \mathrm{~min}$ averaged radar-derived horizontal wind components than between the single cycle components. Nevertheless, the time-averaging serves to reduce the random measurement error associated with individual values. The RMS differences for the 30 min averages, shown by the blue profile in Fig. 11, are reduced to $2.0-3.0 \mathrm{~m} \mathrm{~s}^{-1}$. This suggests that the reduction in random measurement error is more significant that the increase in natural variability.

The orange profile in the right-hand panel of Fig. 11 shows the RMS differences between vertical velocity components at 1 cycle intervals. This uses the first vertical beam dwell from each cycle. It has already been pointed out that significant variability of the vertical velocity over such a short time scale can result from short-period gravity-wave activity. Consequently the values of $0.3-0.4 \mathrm{~m} \mathrm{~s}^{-1}$ are likely to reflect some degree of natural atmospheric variability in addition to the random measurement error. However, this also means that the random measurement error cannot be reduced by time-averaging. Even a small degree of time averaging will begin to reduce the natural variability which is of scientific interest (cf. Weber et al., 1992). An alternative approach for estimating the random measurement error is to restrict attention to those days for which the degree of natural variability is low. A profile (not shown) of the minimum daily RMS values at each range gate gives values of $0.2-0.3 \mathrm{~m} \mathrm{~s}^{-1}$. It is noted that these values are close to the $0.15 \mathrm{~m} \mathrm{~s}^{-1}$ Doppler 
velocity resolution of the spectra. It is also noted that there is no source of independent vertical velocity measurements against which the radar data can be checked.

\section{Discussion}

This study has highlighted the fact that the characteristic time scales, over which significant natural variability can be expected, are quite different for the vertical and for the horizontal components of the wind. This has implications for the optimum way in which DBS observations should be made.

For the most part, the observed vertical wind fluctuations are of small magnitude $\left(\sim 0.1 \mathrm{~m} \mathrm{~s}^{-1}\right)$, which is comparable to the estimated random measurement error $(0.2-$ $0.3 \mathrm{~m} \mathrm{~s}^{-1}$ ). Their contributions to the radial velocities observed by off-vertical beams are so small that they can be ignored without a significant degradation in horizontal wind component accuracy. However, under conditions of shortperiod gravity wave activity, characterised by vertical wind magnitudes of the order of $1 \mathrm{~m} \mathrm{~s}^{-1}$, their contributions to the radial velocities observed by off-vertical beams can be comparable to those from the horizontal wind. Moreover, significant variability can be expected over time scales as short as $2 \mathrm{~min}$, which is considerably less than the BruntVäisälä period (even at stratospheric altitudes). Under such circumstances, irrespective of whether the horizontal wind components are derived from a vertical/off-vertical beam pair (i.e. through Eq. 2) or from a complementary-beam pair (i.e. though Eq. 5), the interval between the two dwells should be minimised.

During the primary validation period, a vertical beam observation is made at every second dwell. The v3 scheme therefore minimises the errors caused by short-period vertical velocity variability by pairing each off-vertical beam dwell with the vertical beam dwell which is closest in time. However, so far, little additional use has been made of the $47 \mathrm{~s}$ interval vertical beam observations. Nevertheless, given that significant variability is expected from one cycle to the next, under conditions of short-period gravity wave activity, it makes sense that vertical beam observations should be made more often than off-vertical beam observations. Moreover, under quiet conditions, the frequency-spectra of vertical velocities can be used to derive the Brunt-Väisälä period (e.g. Röttger, 1980; Ecklund et al., 1985). This, in turn, can be used to derive a profile of temperature (e.g. Revathy et al., 1996). Observation formats encompassing multiple vertical beam dwells are consequently to be encouraged for research applications. The Met Office do not currently make any operational use of the vertical wind estimates.

Increasing the interval between the dwells will increase the chances that the fundamental DBS assumption of a stationary wind field will be invalidated. However, since the degree of natural variability of the horizontal wind is apparently quite low over time scales of up to at least $30 \mathrm{~min}$, this time con- straint is only significant for the dwells required to derive an individual horizontal wind component. It seems likely that the time separation between the pair of dwells required to derive one component of the horizontal wind and the pair required to derive the orthogonal component is less significant. Consequently it is less important to minimise the total cycle length, so long as beam-pairs are appropriately grouped within the sequence.

The Met Office are moving towards increasingly highresolution grids for the nested UK domain of their numerical weather prediction model. Their aim is to be able to accurately forecast small-scale but high-impact phenomena, such as convection. This creates a requirement for increasing the temporal and spatial resolutions of assimilated observations. At present, they assimilate $30 \mathrm{~min}$ averages of v3 wind-profile data, which are known to have a high accuracy. By decreasing the averaging interval, the random measurement error will inevitably rise. Consequently it is unclear as to whether or not higher-time-resolution data will be of any more value. Given that the random measurement error decreases as the averaging interval increases, but that the natural atmospheric variability increases, it is anticipated that there may be an optimal level of averaging for which the two effects are balanced. Identifying such a level will be an important area of future work. This question also has implications for the research use of horizontal winds. Can the variability between single cycle horizontal wind components be guaranteed to reflect natural atmospheric variation as opposed to increased random measurement error?

\section{Conclusions}

This paper has examined a new signal processing scheme for the Doppler Beam Swinging 46.5 MHz wind-profiling radar at Aberystwyth. It is shown that a radial-continuity test is vital for avoiding contamination from unwanted signal components. These are principally a result of ground clutter, interference, and Rayleigh scatter from hydrometeors under stratiform precipitation conditions. In the case of the latter, the scheme must have the ability to resolve partially-overlapping signal components. It is also shown that short-period gravity wave activity can lead to a reduction in horizontal wind component data quality. This is a result of the wind field becoming non-stationary over the temporal and spatial scales encompassed by a cycle of observation.

Acknowledgements. The Aberystwyth MST radar is owned and predominantly funded by the (UK) Natural Environment Research Council (NERC). It is co-funded by the (UK) Met Office. MST radar data (Natural Environment Research Council, 2007) are provided courtesy of NERC and radiosonde data (Met Office, 2007) are provided courtesy of the Met Office through the British Atmospheric Data Centre. The model-comparison statistics were provided by Colin Parrett of the Met Office's Data Assimilation and Observation Monitoring Team. We are grateful to Andrew Birks, 
of the Rutherford Appleton Laboratory, for the many useful discussions which have impacted on numerous aspects of the v1, v2 and v3 signal processing schemes.

Topical Editor U.-P. Hoppe thanks two anonymous referees for their help in evaluating this paper.

\section{References}

Adachi, A., Kobayashi, T., Gage, K. S., Carter, D. A., Hartten, L. M., Clark, W. L., and Fukuda, M.: Evaluation of three-beam and four-beam profiler wind measurement techniques using a five-beam wind profiler and collocated meteorological tower, J. Atmos. Ocean. Tech., 22, 1167-1180, 2005.

Barth, M. F., Chadwick, R. B., and van de Kamp, D. W.: Data processing algorithms used by NOAA's wind profiler demonstration network, Ann. Geophys., 12, 518-528, 1994,

http://www.ann-geophys.net/12/518/1994/.

Boyer, E., Petitdidier, M., and Larzabal, P.: Stochastic Maximum Likelihood (SML) parametric estimation of overlapped Doppler echoes, Ann. Geophys., 22, 3983-3993, 2004,

http://www.ann-geophys.net/22/3983/2004/.

Clothiaux, E. E., Penc, R. S., Thompson, D. W., Ackerman, T. P., and Williams, S. R.: A first-guess feature-based algorithm for estimating wind speed in clear-air Doppler radar spectra, J. Atmos. Ocean. Tech., 11, 888-908, 1994.

Cohn, S. A., Goodrich, R. K., Morse, C. S., Karplus, E., Mueller, S. W., Cornman, L. B., and Weekley, R. A.: Radial velocity and wind measurement with NIMA-NWCA: Comparisons with human estimation and aircraft measurements, J. Appl. Meteorol., 40, 704-719, 2001.

Cornman, L. B., Goodrich, R. K., Morse, C. S., and Ecklund, W. L.: A fuzzy logic method for improved moment estimation from Doppler spectra, J. Atmos. Ocean. Tech., 15, 1287-1305, 1998.

Dibbern, J., Engelbart, D., Goersdorf, U., Latham, N., Lehmann, V., Nash, J., Oakley, T., Richner, H., and Steinhagen, H.: Operational aspects, in: EUR 20614 - COST Action 76 - Development of VHF/UHF wind-profilers and vertical sounders for use in European observing systems - Final report, edited by: Dibbern, J., Monna, W., Nash, J., and Peters, G., pp. 133-224, European Commission, Luxembourg, 2003a.

Dibbern, J., Monna, W., Nash, J., and Peters, G. (Eds.): EUR 20614 - COST Action 76 - Development of VHF/UHF wind profilers and vertical sounders for use in European observing systems Final report, European Commission, 2003b.

Ecklund, W. L., Balsley, B. B., Carter, D. A., Riddle, A. C., Crochet, M., and Garello, R.: Observations of vertical motions in the troposphere and lower stratosphere using three closely spaced ST radars, Radio Sci., 20, 1196-1206, 1985.

Fukao, S., Wakasugi, K., Sato, T., Morimoto, S., Tsuda, T., Hirota, I., Kimura, I., and Kato, S.: Direct measurement of air and precipitation particle motion by very high frequency Doppler radar, Nature, 316, 712-714, 1985.

Gage, K. S. and Nastrom, G. D.: On the spectrum of atmospheric velocity fluctuations seen by MST/ST radar and their interpretation, Radio Sci., 20, 1339-1348, 1985.

Griesser, T. and Richner, H.: Multiple peak processing algorithm for identification of atmospheric signals in Doppler radar wind profiler spectra, Meteorol. Zeitschrift, 7, 292-302, 1998.
Harris, F. J.: On the use of windows for harmonic analysis with the discrete Fourier transform, Proc. IEEE, 66, 51-83, 1978.

Hauf, T.: Aircraft observation of convection waves over southern Germany - a case study, Mon. Weather Rev., 121, 3282-3290, 1993.

Hildebrand, P. H. and Sekhon, R. S.: Objective determination of the noise level in Doppler spectra, J. Appl. Meteorol., 13, 808-811, 1974.

Hocking, W. K., Thayaparan, T., and Franke, S. J.: Method for statistical comparison of geophysical data by multiple instruments which have differing accuracies, Adv. Space Res., 27, 10891098, 2001.

Hooper, D. A.: Signal and noise level estimation for narrow spectral width returns observed by the Indian MST radar, Radio Sci., 34, 859-870, 1999.

Hooper, D. A. and Arvelius, J.: Monitoring of the Arctic winter tropopause: A comparison of radiosonde, ozonesonde and MST radar observations, in: Proceedings of the Ninth International Workshop on Technical and Scientific Aspects of MST Radar, pp. 385-388, Sci. Comment on Sol.-Terr. Phys. Secr., Boulder, Colorado, 2000.

Hooper, D. A. and Astin, I.: The reintroduction of mesospheric observations at Aberystwyth, in: Proceedings of the Eleventh International Workshop on Technical and Scientific Aspects of MST Radar, edited by: Anandan, V. K., pp. 126-130, Macmillan India Ltd., 2007.

Hooper, D. A. and McDonald, A. J.: The unexpected dominance of stratiform precipitation return power over clear-air return power for observations made at lower-VHF, in: Proceedings of the Eleventh International Workshop on Technical and Scientific Aspects of MST Radar, edited by: Anandan, V. K., pp. 36-40, Macmillan India Ltd., 2007.

Hooper, D. A., Arvelius, J., and Stebel, K.: Retrieval of atmospheric static stability from MST radar return signal power, Ann. Geophys., 22, 3781-3788, 2004, http://www.ann-geophys.net/22/3781/2004/.

Hooper, D. A., McDonald, A. J., Pavelin, E., Carey-Smith, T. K., and Pascoe, C. L.: The signature of mid-latitude convection observed by VHF wind-profiling radar, Geophys. Res. Lett., 32, L04808, doi:10.1029/2004GL020401, 2005.

Hooper, D. A., Nash, J., Oakley, T., and Turp, M.: Validation of a new signal processing scheme for the MST radar at Aberystwyth, in: Proceedings of the Eleventh International Workshop on Technical and Scientific Aspects of MST Radar, edited by: Anandan, V. K., pp. 311-315, Macmillan India Ltd., 2007.

Ishihara, M., Kato, Y., Abo, T., Kobayashi, K., and Izumikawa, Y.: Characteristics and performance of the operational wind profiler network of the Japan Meteorological Agency, J. Met. Soc. Japan, 84, 1085-1096, 2006.

Kitchen, M.: Representativeness errors for radiosonde observations, Q. J. Roy. Meteorol. Soc., 115, 673-700, 1989.

Lafaysse, C. (Ed.): EUR 15450 - COST 74 final report - Utilization of UHF/VHF radar wind profiler networks for improving weather forecasts in Europe, European Commission, 1994.

Larsen, M. F.: Can a VHF Doppler radar provide synoptic wind data? A comparsion of 30 days of radar and radiosonde data, Mon. Weather Rev., 111, 2047-2057, 1983.

Larsen, M. F. and Röttger, J.: Observations of thunderstorm reflectivities and Doppler velocities measured at VHF and UHF, J. At- 
mos. Ocean. Tech., 4, 151-159, 1987.

Lucas, C., McKinnon, A., Vincent, R. A., and May, P. T.: Raindrop size distribution retrievals from a VHF boundary layer profiler, J. Atmos. Ocean. Tech., 21, 45-60, 2004.

Luce, H., Fukao, S., M, M. Y., Sidi, C., and Dalaudier, F.: Validation of winds measured by MU radar with GPS radiosondes during the MUTSI campaign, J. Atmos. Ocean. Tech., 18, 817$829,2001$.

May, P. T. and Rajopadhyaya, D. K.: Wind profiler observations of vertical motion and precipitation microphysics of a tropical squall line, Mon. Weather Rev., 124, 621-633, 1996.

McDonald, A. J., Carey-Smith, T. K., Hooper, D. A., Fraser, G. J., and Lublow, B. P.: The effect of precipitation on wind-profiler clear air returns, Ann. Geophys., 22, 3959-3970, 2004, http://www.ann-geophys.net/22/3959/2004/.

Met Office, 2007: High-resolution radiosonde dataset, http://badc. nerc.ac.uk/data/rad-highres, The British Atmospheric Data Centre, 2007.

Morse, C. S., Goodrich, R. K., and Cornman, L. B.: The NIMA method for improved moment estimation from Doppler spectra, J. Atmos. Ocean. Tech., 19, 274-295, 2002.

Muschinski, A.: On a possible effect of Kelvin-Helmholtz instability on VHF-radar observations on the mean vertical wind, J. Appl. Meteorol., 35, 2210-2217, 1996.

Narayana Rao, T., Rao, D. N., and Raghavan, S.: Tropical precipitating systems observed with Indian MST radar, Radio Sci., 34, 1125-1139, 1999.

Nash, J.: Technologies for upper wind measurements, in: EUR 15450 - COST 74 Final Report - Utilization of UHF/VHF radar wind profiler networks for improving weather forecasting in $\mathrm{Eu}-$ rope, edited by: Lafaysse, C., chap. 3, pp. 45-82, European Commission, 1994.

Nash, J. and Ruffieux, D.: Role of wind profilers in observing systems, in: Development of VHF/UHF wind-profilers and vertical sounders for use in European observing systems - Final report, edited by: Dibbern, J., Nash, J., and Peters, G., pp. 9-67, European Union, Brussels, 2003.

Natural Environment Research Council, 2007: NERC MST Radar Facility at Aberystwyth dataset, http://badc.nerc.ac.uk/data/mst, The British Atmospheric Data Centre, 2007.

Ralph, F. M.: Using radar-measured radial vertical velocities to distinguish precipitation scattering from clear-air scattering, J. Atmos. Ocean. Tech., 12, 257-267, 1995.

Revathy, K., Nayar, S. R. P., and Murthy, B. V. K.: Deduction of temperature profile from MST radar observation of vertical wind, Geophys. Res. Lett., 23, 285-288, 1996.

Röttger, J.: Structure and dynamics of the stratosphere and mesosphere revealed by VHF radar investigations, Pure Appl. Geophys., 118, 494-527, 1980.

Röttger, J.: ST radar observations of atmospheric waves over mountainous areas:a review, Ann. Geophys., 18, 750-765, 2000, http://www.ann-geophys.net/18/750/2000/.

Slater, K., Stevens, A. D., Pearmain, S. A. M., Eccles, D., Hall, A., France, L., Roberts, G., Olewicz, Z. K., and Thomas, L.: Overview of the MST radar system at Aberystwyth, in: Proceedings of the Fifth International Workshop on Technical and Scientific Aspects of MST Radar, edited by: Edwards, B., pp. 479482, Sci. Comment on Sol.-Terr. Phys. Secr., Boulder, Colorado, 1992.
Strauch, R. G., Merritt, D. A., Moran, K. P., Earnshaw, K. B., and Kamp, D. V. D.: The Colorado wind-profiling network, J. Atmos. Ocean. Tech., 1, 37-49, 1984.

Strauch, R. G., Weber, B. L., Frisch, A. S., Little, C. G., Merritt, D. A., Moran, K. P., and Welsh, D. C.: The precision and relative accuracy of profiler wind measurements, J. Atmos. Ocean. Tech., 4, 563-571, 1987.

Thomas, L., Astin, I., and Worthington, R. M.: A statistical study of underestimates of wind speeds by VHF radar, Ann. Geophys., 15, 805-812, 1997,

http://www.ann-geophys.net/15/805/1997/.

Vaughan, G.: The UK MST radar, Weather, 57, 69-73, 2002.

Vaughan, G. and Worthington, R. M.: Effects of humidity and precipitation on VHF radar vertical-beam echoes, Radio Sci., 35, 1389-1398, 2000.

Weber, B. L. and Wuertz, D. B.: Comparison of rawinsonde and wind profiler radar measurements, J. Atmos. Ocean. Tech., 7, 157-174, 1990.

Weber, B. L., Wuertz, D. B., Law, D. C., Frisch, A. S., and Brown, J. M.: Effects of small-scale vertical motion on radar measurements of wind and temperature profiles, J. Atmos. Ocean. Tech., 9, 193-209, 1992.

Weber, B. L., Wuertz, D. B., Welsh, D. C., and McPeek, R.: Quality controls for profiler measurements of winds and RASS temperatures, J. Atmos. Ocean. Tech., 10, 452-464, 1993.

Wilczak, J. M., Strauch, R. G., Ralph, F. M., Weber, B. L., Merritt, D. A., Jordan, J. R., Wolfe, D. E., Lewis, L. K., Wuertz, D. B., and Gaynor, J. E.: Contamination of wind profiler data by migrating birds: characteristics of corrupted data and potential solutions, J. Atmos. Ocean. Tech., 12, 449-467, 1995.

Williams, C. R., Ecklund, W. L., and Gage, K. S.: Classification of precipitating clouds in the tropics using $915 \mathrm{MHz}$ wind profilers, J. Atmos. Ocean. Tech., 12, 996-1012, 1995.

Woodman, R. F. and Guillen, A.: Radar observations of winds and turbulence in the stratosphere and mesosphere, J. Atmos. Sci., 31, 493-505, 1974.

Worthington, R. M.: Calculating the azimuth of mountain waves using the effect of tilted fine-scale stable layers on VHF radar echoes, Ann. Geophys., 17, 257-272, 1999, http://www.ann-geophys.net/17/257/1999/.

Worthington, R. M.: All-weather volume imaging of the boundary layer and troposphere using the MU radar, Ann. Geophys., 22, 1407-1419, 2004, http://www.ann-geophys.net/22/1407/2004/.

Worthington, R. M. and Thomas, L.: Radar measurements of critical-layer absorption in mountain waves, Q. J. Roy. Meteorol. Soc., 122, 1263-1282, 1996a.

Worthington, R. M. and Thomas, L.: The measurement of gravity wave momentum flux in the lower atmosphere using VHF radar, Radio Sci., 31, 1501-1517, 1996 b.

Worthington, R. M. and Thomas, L.: The frequency spectrum of mountain waves, Q. J. Roy. Meteorol. Soc., 124, 687-703, 1998.

Wuertz, D. B., Weber, B. L., Strauch, R. G., Frisch, A. S., Little, C. G., Merritt, D. A., Moran, K. P., and Welsh, D. C.: Effects of precipitation on UHF wind profiler measurements, J. Atmos. Ocean. Tech., 5, 450-465, 1988. 